\title{
Selected Lactobacillus strains isolated from sugary and milk kefir reduce Salmonella infection of epithelial cells in vitro
}

\author{
L. Zavala ${ }^{1}$, M.A. Golowczyc ${ }^{1 *}$, K. van Hoorde ${ }^{2,3}$, M. Medrano ${ }^{1}$, G. Huys ${ }^{2,4}$, P. Vandamme and A.G. Abraham $^{1,5}$ \\ ${ }^{1}$ Centro de Investigación y Desarrollo en Criotecnología de Alimentos (CIDCA, CONICET, UNLP), 47 and 116, 1900 La \\ Plata, Argentina; ${ }^{2}$ Laboratory of Microbiology, Department of Biochemistry and Microbiology, Faculty of Sciences, Ghent \\ University, K.L. Ledeganckstraat 35, 9000 Ghent, Belgium; ${ }^{3}$ Laboratory of Biochemistry and Brewing, Faculty of Bioscience \\ Engineering, Ghent University, Valentin Vaerwyckweg 1, 9000 Ghent, Belgium; ${ }^{4}$ BCCM/LMG Bacteria Collection, Department \\ of Biochemistry and Microbiology, Faculty of Sciences, Ghent University, K.L. Ledeganckstraat 35, 9000 Ghent, Belgium; \\ ${ }^{5}$ Área Bioquímica y Control de Alimentos, Facultad de Ciencias Exactas, UNLP, 47 and 116, 1900 La Plata, Argentina; \\ mgolowczyc@yahoo.com.ar
}

Received: 11 January 2016 / Accepted: 14 April 2016

(c) 2016 Wageningen Academic Publishers

\section{RESEARCH ARTICLE}

\begin{abstract}
The isolation of potentially probiotic strains and the subsequent study of their properties are very important steps to gain insight in the health benefits ascribed to sugary and milk kefir. The aim of the present study was to characterise fifteen Lactobacillus strains isolated from these beverages by determining some surface properties and their ability to antagonise enterocyte cell damage after Salmonella infection in vitro. Lactobacillus surface properties were determined by hydrophobicity, autoaggregation, and coaggregation assays with Salmonella. In addition, lactobacilli adhesion to Caco-2/TC-7 cells and the effect on Salmonella invasion were evaluated. Finally, the disassembly of F-actin cytoskeleton on intestinal epithelial cells was assayed in vitro when Salmonella infection was performed in the presence of selected Lactobacillus strains. Ten out of the 15 strains showed a high adhesion capacity to Caco-2/ TC-7 cells. Most of the strains were hydrophilic and non-autoaggregating. Strains isolated from sugary kefir were non-coaggregating with Salmonella, while strains Lactobacillus paracasei CIDCA 83120, 83121, 83123, 83124, 8339, 83102 isolated from milk kefir were able to coaggregate after 1 h. L. paracasei CIDCA 8339 and Lactobacillus kefiri CIDCA 83102 were able to diminish Salmonella invasion to the enterocytes. An antagonistic effect on cytoskeleton disruption elicited by the pathogen was also demonstrated. Our results suggest that both strains isolated from milk kefir could be considered as appropriate probiotic candidates.
\end{abstract}

Keywords: coaggregation, autoaggregation, hydrophobicity, adhesion, invasion

\section{Introduction}

The growing demand for healthier foods is stimulating the innovation and development of new products in the food industry worldwide. Among foods with alleged health claims, the ones containing probiotic strains have received considerable attention. Probiotic strains of lactic acid bacteria (LAB) with the potential to alleviate gastrointestinal diseases, prevent infection of pathogenic bacteria, and degrade carcinogens in the gut, have been used in the manufacture of functional food and pharmaceutical products (Granato et al., 2010).
Although many probiotic microorganisms were originally isolated from the human intestine, other sources such as artisanal fermented products also exist. Kefir is a fermented beverage traditionally consumed for their health promoting properties, and is produced by fermentative activity of 'kefir grains' containing a wide variety of mainly LAB, acetic acid bacteria and yeasts. Milk kefir grains are commonly grown in cow's milk and the fermented product is called 'kefir' (Garrote et al., 2001). Water (or sugary) kefir grains are grown in a solution of raw sugar and water, and the fermented product is known as 'sugary kefir,' 'water kefir' or 'aquakefir' (Gulitz et al., 2011). The 
origin of water kefir remains unclear. It has been postulated that the polysaccharide grains originate from the leaves of the Opuntia cactus fig plant (Gulitz et al., 2011). Pidoux et al. (1990) called them 'sugary kefir grains' in order to differentiate them from the grains used for milk fermentation.

Genera present both in milk and water kefir grains include Lactobacillus, Leuconostoc, Lactococcus, and Acetobacter, and the yeast genera include Kluyveromyces, Candida, Saccharomyces, Torulaspora, Kazachstania, Lachancea, and Yarrowia, while species present in both grains are different (Ferreira-Zanirati et al., 2015; Garrote et al., 2001; Gulitz et al., 2011; Marsh et al., 2013; Miguel et al., 2010). Although there are many studies about the probiotic properties of Lactobacillus isolated from milk kefir (Chen et al., 2012; Golowczyc et al., 2007, 2008; Kakisu et al., 2012; Powell et al., 2007), little is known on the probiotic properties of Lactobacillus isolated from sugary kefir (Ferreira-Zanirati et al., 2015).

Among the most important intestinal pathogens, Salmonella is one of the most extensively studied and characterised. This pathogen is able to interact with the intestinal epithelium brush border, conducting to the formation of typical surface appendages or membrane 'ruffling' (Chen et al., 1996; Ginocchio et al., 1994). Salmonella can then invade intestinal cells by vacuole formation containing Salmonella cells (Steele-Mortimer et al., 2002), causing significant alterations to the F-actin cytoskeleton network (Finlay et al., 1991; Guignot et al., 2004; Méresse et al., 2001). Probiotic strains isolated from different origins have been found to inhibit the infection of intestinal epithelial cells by Salmonella sp. (Burkholder and Bhunia, 2009; Golowczyc et al., 2007; Lee et al., 2003; Schierack et al., 2011).

Both the presence of kefir microorganisms as well as their metabolites (such as lactic acid, carbon dioxide, acetaldehyde, acetoin, alcohol, specific flavour compounds, etc.) contributes to the beneficial effects of this product. Although many probiotic strains are already available for commercial use (Collado et al., 2007), isolation and characterisation of new strains from natural sources with a long tradition of health promotion are still desirable. Kefir grains and fermented products represent a rich source of LAB biodiversity, which contributes to the healthpromoting characteristics traditionally ascribed to this beverage. Moreover, isolation of potentially probiotic strains and subsequent study of their properties are important steps to gain insight in the health benefits ascribed to sugary and milk kefir.

As part of a larger investigation in our working group about the selection and characterisation of new probiotic candidates, the aim of the present study was to characterise fifteen Lactobacillus strains isolated from milk and sugary kefir. We studied both some surface properties as the interaction of selected Lactobacillus isolates with intestinal epithelial cells and their effect on Salmonella infection.

\section{Materials and methods}

\section{Origin of strains, identification and growth conditions}

Milk kefir strains were previously isolated and identified (Hamet et al., 2013). Sugary kefir strains were isolated and identified in Ghent University from a Belgian commercial aquakefir product. Strains were identified through a polyphasic approach combining (GTG) 5 -PCR profiling and partial $16 \mathrm{~S}$ rRNA and/or phenylalanyl-tRNA synthase (PheS) gene sequencing as previously described (Hamet et al., 2013). The Lactobacillus strains used in the present study encompassed the species L. paracasei, L. diolivorans, L. harbinensis, L. hilgardii and L. kefiri, and are listed in Table 1.

Stock cultures were stored in $120 \mathrm{~g} / \mathrm{l}$ non-fat milk solids at $-80{ }^{\circ} \mathrm{C}$. Working cultures were cultivated in De Man, Rogosa, Sharpe broth (MRS, Difco, Detroit, MI, USA) for $48 \mathrm{~h}$ at $30^{\circ} \mathrm{C}$ under static conditions. Salmonella enterica serovar Enteritidis CIDCA 101 (Golowczyc et al., 2007) was used for adhesion/invasion experiments. It was grown in nutrient broth (Biokar Diagnostics, Beauvais, France, ref no. BK003HA) for $18 \mathrm{~h}$ at $37^{\circ} \mathrm{C}$.

\section{Caco-2/TC-7 cell cultures}

Caco-2/TC-7 cells, which model the mature enterocytes of the large intestine, were used. Cells were routinely grown in Dulbecco modified Eagle's minimal essential medium (DMEM) (Gibco BRL Life Technologies Rockville, MD, USA), supplemented with $15 \%(\mathrm{v} / \mathrm{v})$ heat-inactivated (30 min, $60{ }^{\circ} \mathrm{C}$ ) foetal calf serum (GEN SA., Buenos Aires, Argentina), 1\% (w/v) non-essential amino acids (Gibco BRL), penicillin $(12 \mathrm{IU} / \mathrm{ml})$, streptomycin $(12 \mu \mathrm{g} / \mathrm{ml})$, gentamicin $(50 \mu \mathrm{g} / \mathrm{ml})$ and fungizone $(1.25 \mu \mathrm{g} / \mathrm{ml})$ (Parafarm, Saporiti SACIFIA, Buenos Aires, Argentina). Cells were seeded at a concentration of $2.5 \times 10^{5}$ cells per well in 24-well tissue culture plates (GBO Corning, Corning, NY, USA) and incubated at $37{ }^{\circ} \mathrm{C}$ in a $5 \% \mathrm{CO}_{2}-95 \%$ air atmosphere. Culture medium was changed every two days. Caco-2/ TC-7 cells were used at post-confluence after 7 days of culture (differentiated cells) at passages between 23 and 26 .

\section{Hydrophobicity assays for microbial adhesion to hydrocarbons}

The protocol was followed according to Pérez et al. (1998). Briefly, two $\mathrm{ml}$ of Lactobacillus cell suspension $\left(\mathrm{OD}=1\right.$ equivalent to $\left.2 \times 10^{8} \mathrm{cfu} / \mathrm{ml}\right)$ in phosphate buffered saline (PBS) (130 mM sodium chloride, $10 \mathrm{mM}$ sodium 
Table 1. Lactobacillus and Salmonella strains used in the present study, origin and references.

\begin{tabular}{|c|c|c|c|}
\hline Strain $^{1}$ & Species & Origin & Reference \\
\hline$R-40086^{a}$ & L. paracasei & Sugary kefir & This paper \\
\hline$R-40003^{a}$ & L. paracasei & Sugary kefir & This paper \\
\hline$R-40122^{a}$ & L. paracasei & Sugary kefir & This paper \\
\hline$R-39998^{a}$ & L. paracasei & Sugary kefir & This paper \\
\hline$R-40006^{a}$ & L. paracasei & Sugary kefir & This paper \\
\hline$R-40076^{a}$ & L. paracasei & Sugary kefir & This paper \\
\hline $\mathrm{R}-40110^{\mathrm{a}}$ & L. diolivorans & Sugary kefir & This paper \\
\hline$R-40024^{a}$ & L. harbinensis & Sugary kefir & This paper \\
\hline$R-40124^{a}$ & L. hilgardii & Sugary kefir & This paper \\
\hline CIDCA $83120^{b} / R-45465^{a}$ & L. paracasei & Milk kefir & Hamet et al., 2013 \\
\hline CIDCA $83121^{b} /$ R-45466 & L. paracasei & Milk kefir & Hamet et al., 2013 \\
\hline CIDCA $83123^{b} /$ R-45468a & L. paracasei & Milk kefir & Hamet et al., 2013 \\
\hline CIDCA $83124^{b} / R-45469^{a}$ & L. paracasei & Milk kefir & Hamet et al., 2013 \\
\hline CIDCA 8339 / R-45463a & L. paracasei & Milk kefir & Hamet et al., 2013 \\
\hline CIDCA $83102^{b} / R-45464^{a}$ & L. kefir & Milk kefir & Hamet et al., 2013 \\
\hline CIDCA $101^{b}$ & Salmonella enterica serovar Enteritidis & Clinical isolate & Golowczyc et al., 2007 \\
\hline
\end{tabular}

phosphate, $\mathrm{pH} 7.2$ ) were mixed with $0.4 \mathrm{ml}$ of xylene by vortexing for $120 \mathrm{~s}$. The phases were allowed to separate by decantation (5-10 min), and the $\mathrm{A}_{600}$ was measured by using a spectrophotometer (Metrolab 330, Buenos Aires, Argentina). The decrease in the absorbance of the aqueous phase was taken as a measure of the cell surface hydrophobicity $(\mathrm{H} \%)$, as calculated with the formula: $\mathrm{H} \%$ $=\left(A_{0}-A\right) / A_{0} \times 100$, where $A_{0}$ and $A$ are the absorbance before and after extraction with xylene, respectively.

\section{Autoaggregation assays}

Lactobacillus cells were harvested at stationary phase, collected by centrifugation $(10,000 \times g$ for $10 \mathrm{~min})$, washed twice, and resuspended in PBS. In all experiments, Lactobacillus suspensions were standardised to $\mathrm{OD}_{600}=1.0$ $\left(2 \times 10^{8} \mathrm{cfu} / \mathrm{ml}\right)$. Optical density was measured in a spectrophotometer (Metrolab 330) at regular intervals without disturbing the microbial suspension to determine the kinetics of sedimentation. The autoaggregation coefficient $(\mathrm{AC})$ was calculated at $1 \mathrm{~h}$ according to Golowczyc et al. (2007) as: $\mathrm{AC}=\left[\left(\mathrm{OD}_{\mathrm{t}}-\mathrm{OD}_{\mathrm{i}}\right) / \mathrm{OD}_{\mathrm{i}}\right] \times$ 100 where $\mathrm{OD}_{\mathrm{i}}$ is the initial optical density at $600 \mathrm{~nm}$ of the microbial suspension and $\mathrm{OD}_{\mathrm{t}}$ is the optical density at time $t$.

\section{Coaggregation assays}

Lactobacillus cell suspensions were obtained as described above. Salmonella cells were harvested in stationary phase by centrifugation for $4 \mathrm{~min}$ at 5,000 $\times g$ and resuspended in PBS. $1 \mathrm{ml}$ of Lactobacillus suspension $\left(2 \times 10^{8} \mathrm{cfu} / \mathrm{ml}\right)$ and $1 \mathrm{ml}$ of Salmonella suspension $\left(2 \times 10^{8} \mathrm{cfu} / \mathrm{ml}\right)$ were mixed in glass test tubes and incubated at $37^{\circ} \mathrm{C}$. Optical density was measured at zero time and after 1 and $20 \mathrm{~h}$ without shaking the glass tube. Coaggregation coefficient (CC) was calculated at time $t$ according to Golowczyc et al. (2007) as: $C C=\left[\left(O D_{t}-O D_{i}\right) / O D_{i}\right] \times 100$ where $O D_{i}$ is the initial optical density at $600 \mathrm{~nm}$ of the microbial suspension and $\mathrm{OD}_{\mathrm{t}}$ is the optical density at time $t$. Coaggregation coefficient $(\mathrm{CC})$ was calculated as stated before but subtracting the corresponding aggregation coefficient (AC) of each strain obtained as previously explained.

\section{Lactobacillus adhesion to Caco-2/TC-7 cells}

The adhesion assay was carried out according to Golowczyc et al. (2007). Briefly, Caco-2/TC-7 monolayers at postconfluence were washed twice with sterile PBS buffer $(\mathrm{pH}$ 7.2) and were incubated with $0.5 \mathrm{ml}$ of each Lactobacillus suspension $\left(1 \times 10^{8} \mathrm{cfu} /\right.$ well $)$ and $0.5 \mathrm{ml}$ of DMEM for $1 \mathrm{~h}$ at $37{ }^{\circ} \mathrm{C}$ in a $5 \% \mathrm{CO}_{2}-95 \%$ air atmosphere. Then, monolayers were washed and lysed by adding $1 \mathrm{ml}$ of sterile distilled water. To determine the number of viable lactobacilli that adhered to Caco-2/TC-7 cells, appropriate dilutions in $0.1 \%(\mathrm{w} / \mathrm{v})$ tryptone solution in water were plated on MRS and colony counts were performed after $48 \mathrm{~h}$ incubation. Experiments were carried out in triplicate on three consecutive cell passages. 


\section{Salmonella association and invasion assays}

Assays were carried out according to Golowczyc et al. (2007). Briefly, to evaluate Salmonella association, $0.5 \mathrm{ml}$ of Salmonella suspension $\left(1 \times 10^{8} \mathrm{cfu} /\right.$ well $)$ and $0.5 \mathrm{ml}$ of DMEM were added to each well and incubated $1 \mathrm{~h}$ at $37^{\circ} \mathrm{C}$ in a $5 \% \mathrm{CO}_{2}-95 \%$ air atmosphere. Then, monolayers were washed three times and lysed by adding sterile water. Appropriate dilutions in $0.1 \%$ tryptone were plated and colony counts were performed in order to determine the number of associated (adhering plus invading) viable cells.

Two different types of experiments were performed to evaluate Salmonella invasion: (1) Caco-2/TC-7 cells were first preincubated with $0.5 \mathrm{ml}$ Lactobacillus suspension $\left(1 \times 10^{8} \mathrm{cfu} /\right.$ well $)$ for $1 \mathrm{~h}$ at $37^{\circ} \mathrm{C}$ as described above and washed; then, $0.5 \mathrm{ml}$ of Salmonella suspension $\left(1 \times 10^{8}\right.$ $\mathrm{cfu} /$ well) and $0.5 \mathrm{ml}$ of DMEM was added to each well. Control cells were preincubated $1 \mathrm{~h}$ with PBS (without Lactobacillus suspension) (2) Lactobacillus $\left(1 \times 10^{8} \mathrm{cfu} /\right.$ well) and Salmonella $\left(1 \times 10^{8} \mathrm{cfu} /\right.$ well $)$ suspensions were mixed and coincubated in PBS (pH 7.2) for $1 \mathrm{~h}$ at $37^{\circ} \mathrm{C}$; then, $0.5 \mathrm{ml}$ of the mixture and $0.5 \mathrm{ml}$ of DMEM was added to each well. Salmonella control was coincubated with PBS (without Lactobacillus suspension). At the end of coincubation Salmonella count was performed and no evidence of a decrease in viable cells during this period was observed. With the aim of counting only internalised bacteria, Caco-2/TC-7 cells were washed twice with PBS and incubated for $1 \mathrm{~h}$ at $37^{\circ} \mathrm{C}$ with $0.5 \mathrm{ml}$ of gentamicin $100 \mu \mathrm{g} / \mathrm{ml}$ (Sigma-Aldrich, St. Louis, MO, USA) in PBS. Next, the monolayers were washed twice with PBS, lysed by adding sterile water for $1 \mathrm{~h}$ and colony counts were performed on nutrient agar (Biokar Diagnostics, ref no. BK021HA). Experiments were carried out in triplicate on three consecutive cell passages.

\section{F-actin cytoskeleton labelling}

The F-actin cytoskeleton was labelled with fluoresceinlabelled phalloidin (Coconier et al., 2000). Briefly, monolayers of Caco-2/TC-7 cells prepared on glass coverslips were incubated for $1 \mathrm{~h}$ with $0.5 \mathrm{ml}$ selected Lactobacillus strains $\left(1 \times 10^{8} \mathrm{cfu} /\right.$ well). Next, monolayers were washed twice with PBS and were subsequently infected with Salmonella $\left(1 \times 10^{8} \mathrm{cfu} /\right.$ well $)$ for $1 \mathrm{~h}$. After infection, cells were washed with PBS and fixed with $3 \%(\mathrm{w} / \mathrm{v})$ paraformaldehyde in PBS for $15 \mathrm{~min}$. Samples were then treated with $50 \mathrm{mM} \mathrm{NH}_{4} \mathrm{Cl}$ for 10 min to block aldehyde functions, permeabilised for 4 min with Triton X-100, and incubated for $45 \mathrm{~min}$ with $1 \mu \mathrm{g} / \mathrm{ml}$ fluorescein-labelled phalloidin (Sigma-Aldrich). Then, the coverslips were mounted in $50 \%(\mathrm{v} / \mathrm{v})$ glycerol- $0.1 \%(\mathrm{v} / \mathrm{v})$ sodium azide in PBS. Samples were examined by an inverted microscope system (Nikon TI-Eclipse) coupled to NIS-Elements imaging software (Nikon Instruments Inc., Tokyo, Japan).

\section{Data analysis}

Results were expressed as means \pm standard deviation of at least three separate duplicate experiments. Statistical analysis was performed with the GraphPad Prism version 5.0 for Windows (San Diego, CA, USA). A simple analysis of variance (ANOVA) to determine differences was used. The significant differences between the mean values of each experiment were determined by the Tukey test (confidence interval 95\%).

\section{Results}

\section{Adhesion to Caco-2/TC7 cells, hydrophobicity and autoaggregation of Lactobacillus isolates}

The studied strains showed variable adhesion values to intestinal cells. L. paracasei strains R-40076 and R-40003 isolated from sugary kefir showed adhesion values lower than $2 \log _{10} \mathrm{cfu} /$ well, while the rest of the studied strains showed adhesion values higher than $4 \log _{10} \mathrm{cfu} /$ well (Figure 1).

Most Lactobacillus strains were hydrophilic when tested with xylene as they exhibited hydrophobicity percentages $<5 \%$. Only L. diolivorans R-40110 isolated from sugary kefir, showed a hydrophobicity percentage of $18.1 \pm 2.5 \%$.

Autoaggregation ability of lactobacilli depended on the strains. L. diolivorans R-40110, L. paracasei strains R-40003 and R-40076, showed autoaggregation percentages $>10 \%$, while other strains autoaggregated less than 9\% (Table 2).

\section{Interaction of lactobacilli with Salmonella and implications on pathogen invasion}

Coaggregation of total lactobacilli with Salmonella was evaluated at 1 and $20 \mathrm{~h}$. Strains isolated from milk kefir showed the highest coaggregation percentages after $1 \mathrm{~h}$ (between 27 and 39\%) compared to strains isolated from sugary kefir. After 20 h, Lactobacillus showed different percentages of coaggregation with Salmonella. L. paracase $i$ strains R-40086 and R-39998, L. diolivorans R-40110 and $L$. hilgardii $\mathrm{R}-40124$ showed coaggregation values lower than $2.2 \%$, while L. paracasei CIDCA 8339 and L. kefiri CIDCA 83102 showed the highest coaggregation coefficient (62.6 and $72.5 \%$, respectively) (Table 2).

Ability to inhibit pathogen invasion to enterocytes was performed only for strains with high adhesion ability to Caco-2/TC-7 cells. L. paracasei strains R-40086, R-39998, CIDCA 8339, CIDCA 83120, CIDCA 83121, CIDCA 83123, and CIDCA 83124, L. diolivorans R-40110, L. hilgardii R-40124 and L. kefiri CIDCA 83102 were coincubated with Salmonella, after that, the monolayers Caco-2/TC-7 were infected and the number of internalised Salmonella was 


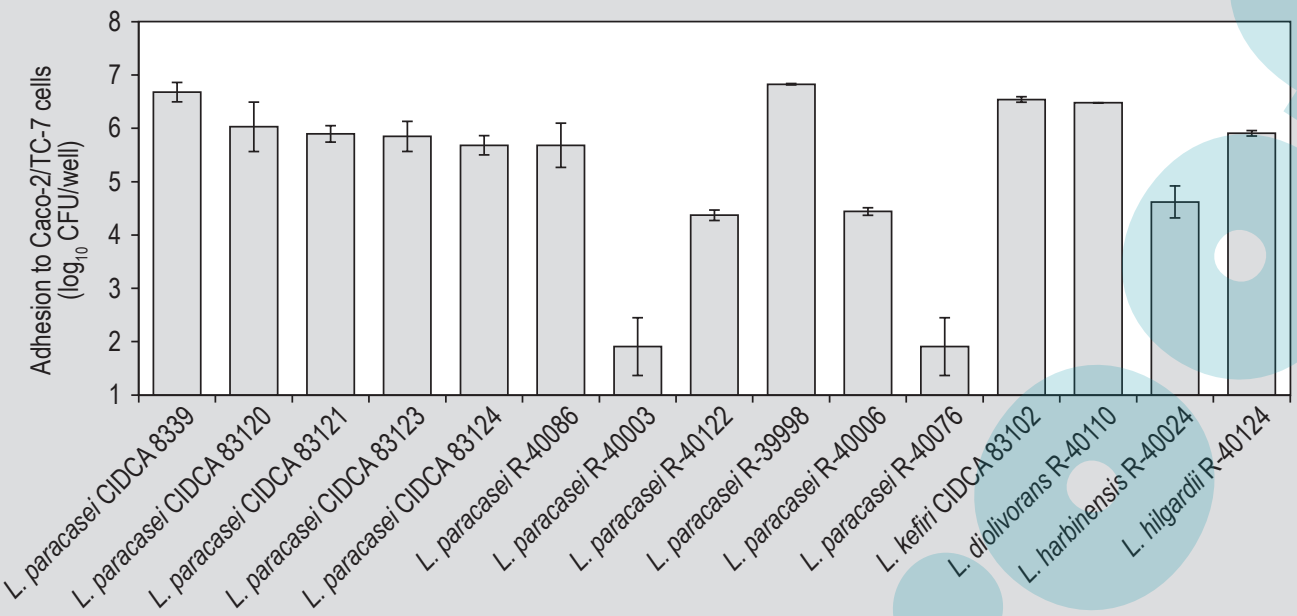

Figure 1. Lactobacilli adhesion to Caco-2/TC7 cells. Adhesion of lactobacilli isolated from sugary and milk kefir to Caco-2/ TC-7 cells. Values were obtained by calculating the ratio of adhering lactobacilli $\left(\log _{10}\right.$ cfu/well) \pm standard deviation of three independent assays.

Table 2. Coaggregation of Lactobacillus strains with Salmonella enterica serovar Enteritidis (CC) and Lactobacillus autoaggregation coefficient (AC).

\begin{tabular}{|c|c|c|c|}
\hline \multirow[t]{2}{*}{ Strain } & \multicolumn{2}{|c|}{$\%$ CC with Salmonella 1} & \multirow[t]{2}{*}{$\% A C^{2}(1 \mathrm{~h})$} \\
\hline & $1 \mathrm{~h}$ & $20 \mathrm{~h}$ & \\
\hline R-40086 & $0.2 \pm 0.1$ & $2.2 \pm 0.1$ & $6.0 \pm 0.4$ \\
\hline R-40003 & $4.3 \pm 0.1$ & $34.0 \pm 0.1$ & $10.0 \pm 0.6$ \\
\hline R-40122 & $5.5 \pm 0.1$ & $32.2 \pm 0.1$ & $0.2 \pm 0.1$ \\
\hline R-39998 & $0.3 \pm 0.1$ & $1.3 \pm 0.5$ & $4.2 \pm 0.3$ \\
\hline R-40006 & $5.2 \pm 0.1$ & $31.1 \pm 0.1$ & $1.3 \pm 0.4$ \\
\hline R-40076 & $11.2 \pm 0.1$ & $43.5 \pm 0.1$ & $13.0 \pm 0.3$ \\
\hline R-40110 & $1.0 \pm 0.1$ & $1.0 \pm 0.3$ & $14.6 \pm 0.3$ \\
\hline R-40024 & $3.4 \pm 0.1$ & $46.5 \pm 0.1$ & $0.6 \pm 0.5$ \\
\hline R-40124 & $0.4 \pm 0.1$ & $1.4 \pm 0.1$ & $8.6 \pm 0.5$ \\
\hline CIDCA 83120 & $29.2 \pm 0.8$ & $39.7 \pm 0.5$ & $4.0 \pm 0.2$ \\
\hline CIDCA 83121 & $33.0 \pm 0.3$ & $52.3 \pm 2.3$ & $3.0 \pm 0.3$ \\
\hline CIDCA 83123 & $31.4 \pm 0.5$ & $41.7 \pm 0.7$ & $3.0 \pm 0.7$ \\
\hline CIDCA 83124 & $39.2 \pm 1.6$ & $47.7 \pm 1.8$ & $4.0 \pm 0.8$ \\
\hline CIDCA 8339 & $32.0 \pm 2.3$ & $62.6 \pm 2.8$ & $4.3 \pm 0.1$ \\
\hline CIDCA 83102 & $27.6 \pm 5.0$ & $72.5 \pm 7.1$ & $5.2 \pm 0.1$ \\
\hline \multicolumn{4}{|c|}{$\begin{array}{l}{ }^{1} \text { Values are the mean of } \mathrm{CC} \pm \text { standard deviation obtained from three } \\
\text { independent assays. } \mathrm{CC} \text { was calculated at } 1 \text { and } 20 \mathrm{~h} \text { at } 37^{\circ} \mathrm{C} \text { as indicated } \\
\text { in materials and methods. } \\
{ }^{2} \text { Values are the mean of } \mathrm{AC} \pm \text { standard deviation obtained from three } \\
\text { independent assays. } \mathrm{AC} \text { was calculated at } 1 \mathrm{~h} \text { as indicated in materials } \\
\text { and methods. }\end{array}$} \\
\hline
\end{tabular}

determined. While strains $L$. paracasei R-40086, R-39998, $L$. hilgardii R-40124 and $L$. diolivorans R-40110 did not protect the monolayers from Salmonella invasion, L. paracasei strains CIDCA 8339, CIDCA 83120, CIDCA 83121, CIDCA 83123, CIDCA 83124 and L. kefiri CIDCA 83102 significantly diminished the pathogen invasion $(P \leq 0.05)$ (Figure 2). Strains that showed a protective effect against Salmonella invasion were selected to conduct subsequent assays to evaluate barrier effect against Salmonella association/invasion to enterocytes.

\section{Barrier effect of Lactobacillus against Salmonella association/invasion to Caco-2/TC-7 cells}

As shown above, $L$. paracasei strains CIDCA 8339, CIDCA 83120, CIDCA 83121, CIDCA 83123, CIDCA 83124 and L. kefiri CIDCA 83102 protected Caco-2/TC-7 cells from Salmonella invasion when these strains were allowed to coaggregate with the pathogen. Therefore, these strains were incubated with the intestinal cells previous to Salmonella infection to evaluate if the pathogen could adhere and/or invade the enterocytes.

L. paracasei strains CIDCA 8339, CIDCA 83123 and CIDCA 83124 and L. kefiri CIDCA 83102 diminished Salmonella association (Figure 3A) while only the strains L. paracasei CIDCA 8339 and L. kefiri CIDCA 83102 were able to diminish the invasion to the enterocytes compared to Salmonella control (Figure 3B).

As the F-actin cytoskeletal rearrangement is one of the steps accompanying Salmonella entry into epithelial cells, and taking into account that L. paracasei CIDCA 8339 and 


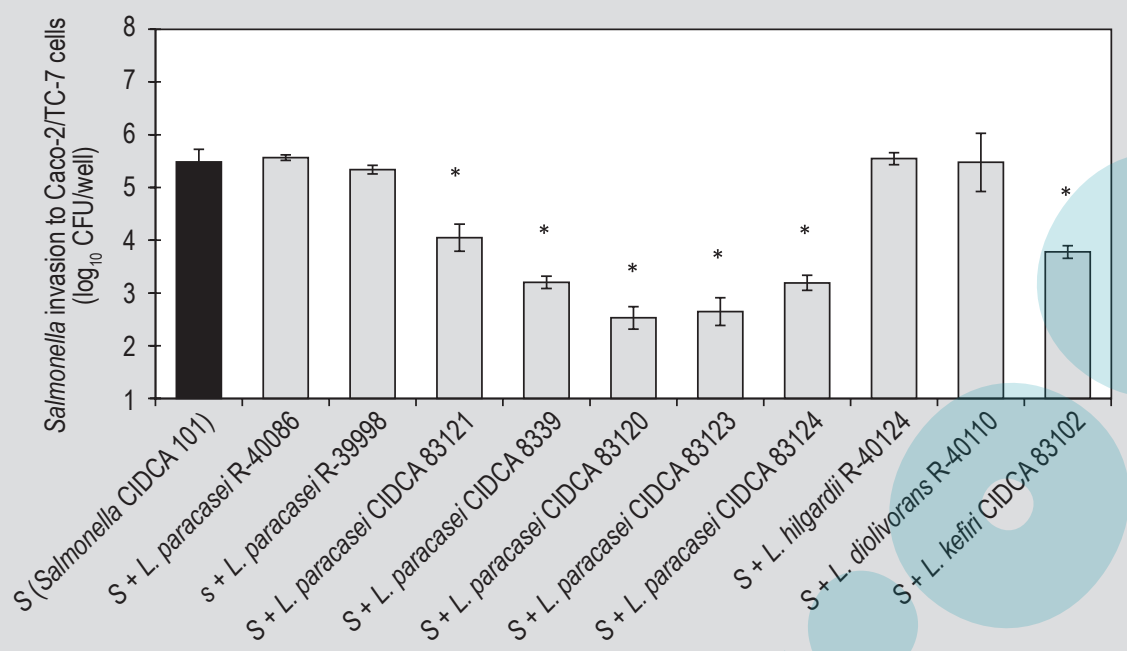

Figure 2. Salmonella invasion to Caco-2/TC7 cells after coincubation with Lactobacillus strains. Salmonella invasion $\left(\log _{10} \mathrm{cfu/}\right.$ well) to Caco-2/TC7 cells after the coincubation $\left(1 \mathrm{~h}\right.$ at $\left.37^{\circ} \mathrm{C}\right)$ of the pathogen with the selected strains L. paracasei (R-40086, R-39998, CIDCA 8339, 83120, 83121, 83123, 83124), L. diolivorans (R-40110), L. hilgardii (R-40124) and L. kefiri (CIDCA 83102). Results are the mean from 3 independent determinations \pm standard deviation. * represent statistically significant differences $(P \leq 0.05)$ compared to infection control (Salmonella).
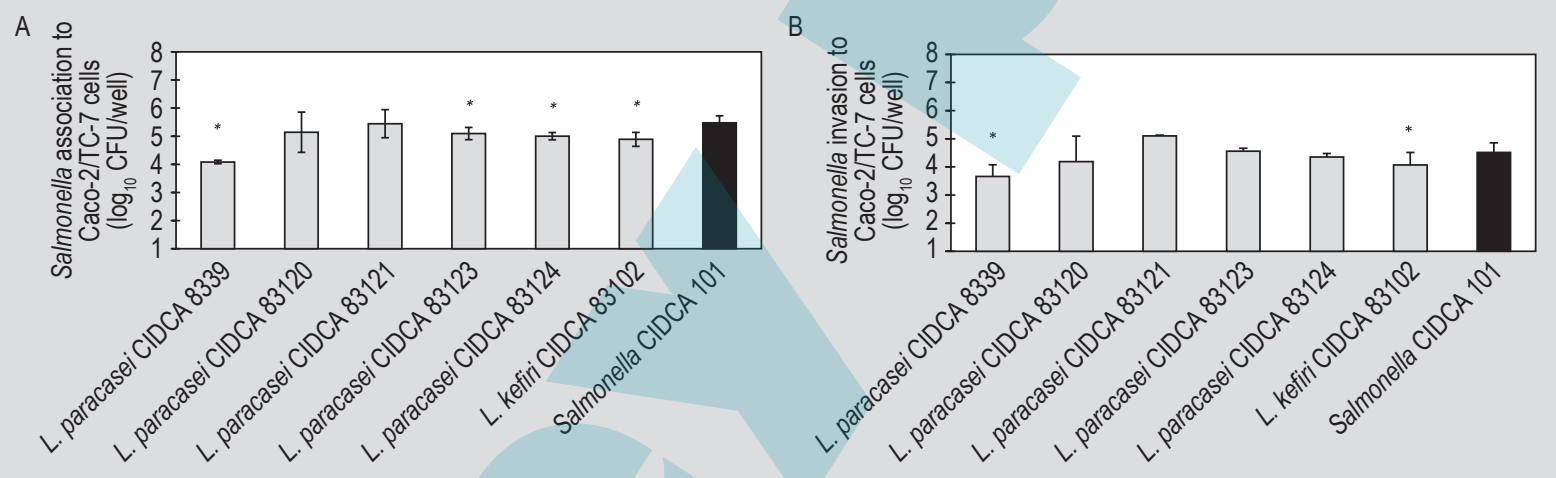

Figure 3. (A) Salmonella association. Barrier effect of Lactobacillus against Salmonella association. Salmonella association $\left(\log _{10}\right.$ cfu/well) to Caco-2/TC7 cells after the coincubation of the eukaryotic cells with the selected strains L. paracasei (CIDCA 8339, $83120,83121,83123,83124)$ and $L$. kefiri (CIDCA 83102). Results are the mean from 3 independent determinations \pm standard deviation. * represent statistically significant differences $(P \leq 0.05)$ compared to association control (Salmonella). (B) Salmonella invasion. Barrier effect of Lactobacillus against Salmonella invasion. Salmonella invasion ( $\log _{10}$ cfu/well) to Caco-2/TC7 cells after the coincubation of the eukaryotic cells with the selected strains $L$. paracasei (CIDCA 8339, 83120, 83121, 83123, 83124) and L. kefiri (CIDCA 83102). Results are the mean from 3 independent determinations \pm standard deviation. ${ }^{*}$ represent statistically significant differences $(P \leq 0.05)$ compared to invasion control (Salmonella).

L. kefiri CIDCA 83102 strains demonstrated to be able to diminish Salmonella invasion to enterocytes, cytoskeleton integrity was investigated.

Salmonella infection of Caco-2/TC-7 cells resulted in cytoskeleton disassembly (Figure 4B), showing characteristic dense spots of intense localised accumulations of F-actin, without detaching the cells to the surface of the well.
Interestingly, the preincubation of the enterocytes with $L$. kefiri CIDCA 83102 and L. paracasei CIDCA 8339 strains (Figure 4C and 4D), resulted into an antagonist effect of cytoskeleton disorganisation elicited by the pathogen, preserving the integrity of the monolayers and showing a pattern similar to the control without treatment (Figure 4A). 

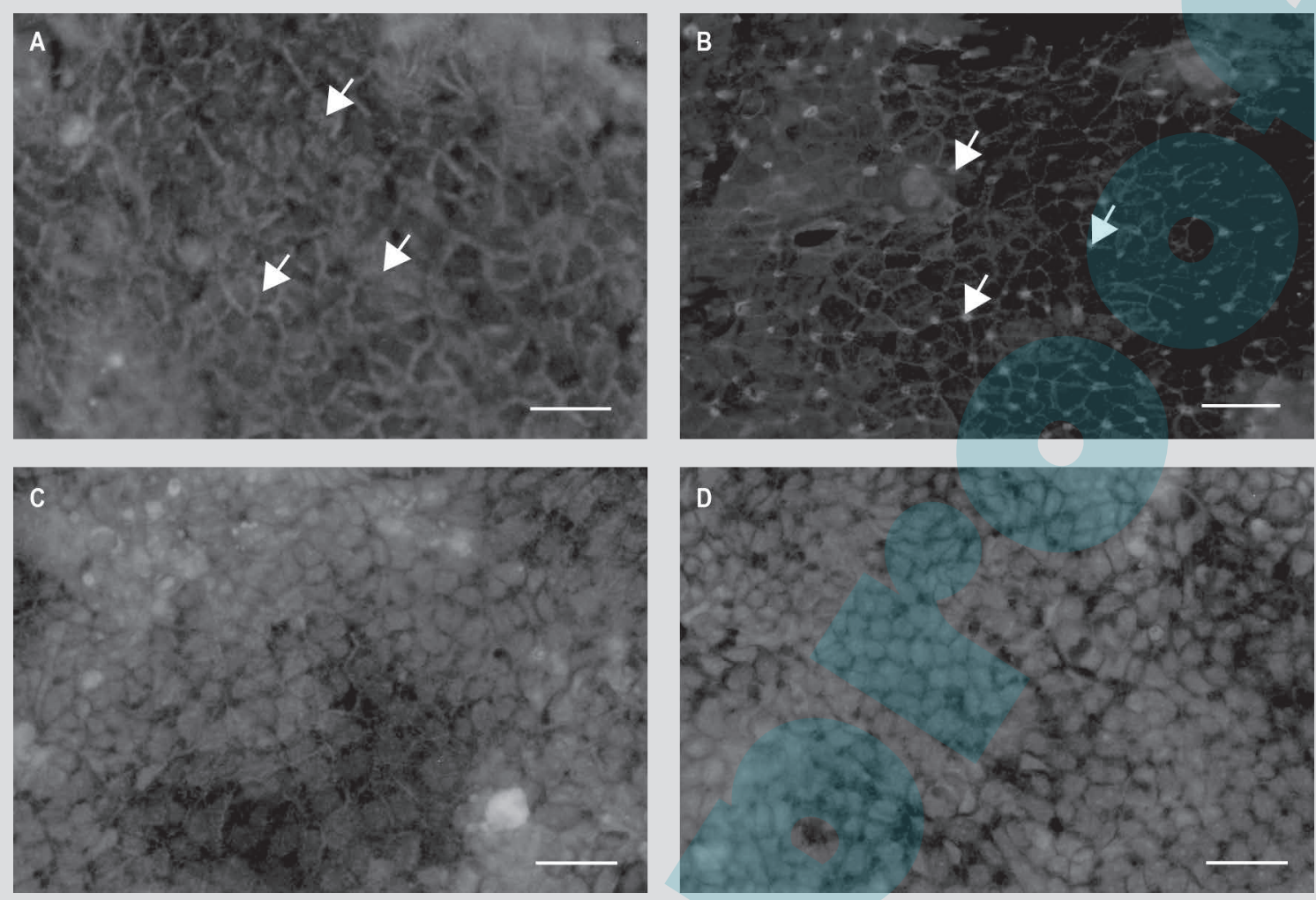

Figure 4. Cytoskeleton integrity. Micrographs showing localisation of F-actin in Caco-2/TC-7 cells. (A) Control uninfected cells treated with DMEM. The fine flocculated centrally located in the cells represents microvilli-associated F-actin (arrows). (B) Cells infected for $2 \mathrm{~h}$ with Salmonella. The localised dense spots of fluorescence (arrowheads) represent $\mathrm{F}$-actin accumulation characteristically triggered by the pathogen. (C and D) Cells preincubated with $L$. paracasei strains CIDCA 8339 and CIDCA 83102, respectively, before Salmonella infection. Cells did not show the F-actin disassembly triggered by Salmonella, as no dense spots were observed. Lactobacillus incubation with Caco-2/TC7 cells showed an aspect similar to control cells without treatment (data not shown). Bar: $10 \mu \mathrm{m}$.

\section{Discussion}

For the development of novel probiotic foods the selection and evaluation of new and more specific probiotic microorganisms, that provides health benefits in the human population and improve certain functional disorder, is a continuous challenge. Although commonly the origin of these strains is the human gut, traditional fermented foods are an alternative source. In particular, Lactobacillus seems to possess the functional criteria required for probiotic candidates, i.e. cell adherence, coaggregation and antagonistic activity against Salmonella and technological features that allow applications in food industry (Foligné et al., 2013). In this paper, we evaluated the probiotic properties of 15 Lactobacillus strains isolated from sugary and milk kefir.

Probiotic action could be associated with several mechanisms such as: production of antimicrobial substances, competitive exclusion, modulation of the immune response, alteration of intestinal bacterial metabolic activity, beneficial alteration of microecology in the human intestine, and inhibition of bacterial translocation (Servin, 2004). Many of the cited mechanisms could be related to bacterial surface properties (Cesena et al., 2001; Pérez et al., 1998; Polak-Berecka et al., 2014). Auto and coaggregation as well as adhesion to intestinal epithelial cells are among the most important surface-related characteristics of probiotics. They are conditioned by a plethora of factors such as surface teichoic and lipoteichoic acids or S-layer proteins (SchärZammaretti and Ubbink, 2003), and exopolysaccharide synthesis (Lebeer et al., 2010; Walter et al., 2008) that may positively or negatively affect adherence to other cells (Goh and Klaenhammer, 2010; Lahtinen and Ouwehand, 2009; Polak-Berecka et al., 2014).

Coaggregation properties of probiotic strains with pathogens may also be considered as desirable because bacterial clusters could hinder the movement of the pathogens through the mucus, preventing them to reach and colonise the epithelial cells (Collado et al., 2008; Gueimonde et al., 2006). In addition, probiotic microorganisms with the 
ability to coaggregate with pathogenic bacteria may have an advantage over non-coaggregating because pathogens can be trapped by the probiotic bacteria and could be more easily removed from the intestinal environment preventing a possible infection by pathogenic bacteria (Boris et al., 1997; Del Re et al., 1998). Different surface molecules are involved in bacteria interactions (Tareb et al., 2013), in consequence auto and coaggregation are strainspecific properties (Collado et al., 2008). Results were in concordance with previous studies which demonstrated that autoaggregation values could be higher, similar (Tareb et al., 2013; Xu et al., 2009), or lower (Ferreira et al., 2011) than coaggregation.

In the present study, when Lactobacillus strains were co-incubated for $1 \mathrm{~h}$ with Salmonella prior to Caco-2/ TC7 cells infection, it was observed that the strains with coaggregation coefficients higher than $27 \%$ significantly reduced the invasion of this pathogen. In contrast, non-coaggregating strains had no effect on Salmonella invasion. These results suggest that the Lactobacilluspathogen interaction begins before both microorganisms interact with the intestinal epithelium. As a result of this interaction, lactobacilli may create a microenvironment that could affect Salmonella virulence factors expression. Likewise, Golowczyc et al. (2007) previously observed that co-incubation of Salmonella with coaggregating $L$. kefiri strains significantly decreased the adhesion and invasion ability of this pathogen to Caco-2/TC-7 cells, and this was not observed with non-coaggregating $L$. kefiri strains. Valeriano et al. (2014) reported a positive correlation between coaggregation and displacement of Escherichia coli. However, the same authors concomitantly found a correlation between adhesion, aggregation and hydrophobicity, whereas no such correlation was observed between these parameters in the present study. Cell surface hydrophobicity is one of the most important factors controlling adhesion of microorganisms to surfaces (Schillinger et al., 2005). According to Otero et al. (2004) bacterium classified as hydrophobic can be considered as able to mediate adhesion. In our work no correlation was observed between adhesion and hydrophobicity. Only one strain showed a high percentage of hydrophobicity $(L$. diolivorans $\mathrm{R}-40110$ ) and proved to have a high adhesion compared with the other strains. However, many other strains with high adhesion were hydrophilic.

Thus, different mechanisms can be utilised by probiotic strains to exert an inhibitory effect against Salmonella: adhesion to the intestinal epithelium (and thus create a barrier effect and prevent pathogen adhesion or invasion) or through a coaggregation effect with the pathogen. Our results showed that some strains with high adhesion capacity were non-coaggregating (i.e. R-39998), while other strains with high percentages of coaggregation showed variable adhesion capacity (CIDCA 83120, 83121, 83123,
$83124,8339,83102)$. These are independent mechanisms that could contribute to inhibit the adhesion and invasion of Salmonella.

In addition to nutrient absorption, the gut barrier is also responsible for the organisation of host defence mechanisms against harmful macromolecules and pathogen invasion. In this study, strains with the highest coaggregation coefficients with Salmonella and with a high or medium ability to adhere to epithelial cells were selected to assess their potential contribution to the gut barrier. Four out of the six coaggregating strains were able to reduce association with Salmonella, and only 2 strains (i.e. L. paracasei CIDCA 8339 and L. kefiri CIDCA 83102) were able to reduce Salmonella invasion to intestinal cells being this two strains the ones that had the highest adhesion ability. These results are in concordance to previous reports which comments that the inhibition of Salmonella sp. adhesion to Caco-2 cells in vitro was directly related with the adhesion ability of the Lactobacillus strains (Fernandez et al., 2003; Lee et al., 2003; Santos et al., 2003).

F-actin network disassembly is considered as one of the main mechanisms by which pathogenic microorganisms structurally and functionally alter the host cells, and this has also particular relevance for intestinal epithelial barrier maintenance (Bernet-Camard et al., 1996; Medrano et al., 2009). By this strategy, pathogens could associate to cell surface or even invade them. In the present study, we demonstrated that strains $L$. paracasei CIDCA 8339 and L. kefiri CIDCA 83102 were able to diminish Salmonella invasion and we also demonstrated an antagonistic effect on cytoskeleton disruption elicited by the pathogen. This may result from the blocking of the initial crosstalk between Salmonella and Caco-2/TC-7 cell effectors. By coaggregating with the pathogen, or by direct association to the intestinal cells, these lactobacilli can protect eukaryotic cells from Salmonella invasion and thus diminish cytoskeleton disassembly. Lactobacillus protection against cytoskeleton disorganisation elicited by Salmonella in similar in vitro models was previously reported (Coconnier et al., 2000; Li et al., 2011). Recently, Yu et al. (2015) found that Lactobacillus fructosus C2 was able to antagonise Salmonella Typhimurium alterations on Caco-2 monolayers tight junctions, while Koninkx et al. (2010) found that probiotic strains of Lactobacillus sp. stabilised the transepithelial barrier integrity of Caco-2 cells when they were preincubated before Salmonella enterica infection. These mechanisms should not be ruled out as an alternative pathway for the observed antagonism on cytoskeleton disruption and/or pathogen invasion.

In our research group, it was demonstrated that $L$. paracasei CIDCA 8339 produces high molecular weight exopolysaccharides affecting the viscosity of the fermented milk (Hamet et al., 2015). Exopolysaccharide production 
could also be related to the surface properties of probiotic strains (Lebeer et al., 2010; Walter et al., 2008), and this could explain the results obtained with this particular strain. This strain could be valuable candidate for texture improvement of fermented milk products. The ability to produce exopolysaccharides together with the results demonstrated in this work suggest that $L$. paracasei CIDCA 8339 is a good candidate as a probiotic microorganism and would be feasible to incorporate into a food matrix.

\section{Conclusions}

Our results suggest that $L$. kefiri strain CIDCA 83102 and $L$. paracasei strain CIDCA 8339 isolated from milk kefir could be considered as appropriate probiotic candidates. Both strains showed adhesion ability to enterocytes, inhibited Salmonella association/invasion and prevented cytoskeleton disorganisation on in vitro assays. Both strains, alone or in combination with other probiotics, may prove useful in future applications. Furthermore, being food isolated strains they are pre-adapted to the food environment, which might be more feasible for their incorporation into healthy functional foods. Future studies will be addressed on the ability of these lactobacilli strains to inhibit infection by other enteropathogens, as well as their role of evoking beneficial effects in animal models. More studies should be conducted for the inclusion of these selected strains into functional foods.

\section{Acknowledgments}

This work was performed in the framework of the MINCYT-FWO Cooperation project 09-01. The authors gratefully acknowledge the financial support provided by Consejo Nacional de Investigaciones Científicas y Técnicas (CONICET) of Argentina, Universidad de La Plata (UNLP), Agencia Nacional de Promoción Científica y Tecnológica.

\section{References}

Bernet-Camard, M.F., Coconnier, M.H., Hudault, S. and Servin, A.L., 1996. Pathogenicity of the diffusely adhering strain Escherichia coli C1845: F1845 adhesin-decay accelerating factor interaction, brush border microvillus injury, and actin disassembly in cultured human intestinal epithelial cells. Infection and Immunity 64: 1918-1928.

Boris, S., Suarez, J.E. and Barbes, C., 1997. Characterization of the aggregation promoting factor from Lactobacillus gasseri a vaginal isolate. Journal of Applied Microbiology 83: 413-420.

Burkholder, K.M. and Bhunia, A.K., 2009. Salmonella enterica serovar Typhimurium adhesion and cytotoxicity during epithelial cell stress is reduced by Lactobacillus rhamnosus GG. Gut Pathogens 1: 1-14.

Cesena, C., Morelli, L., Alander, M., Siljander, T., Tuomola, E., Salminen, S., Mattila-Sandholm, T., Vilpponen-Salmela, T. and Von Wright, A., 2001. Lactobacillus crispatus and its no aggregating mutant in human colonization trials. Journal of Dairy Science 84: 1001-1010.
Chen, L.M., Hobbie, S. and Galán, J.E., 1996. Requirement of CDC42 for Salmonella-induced cytoskeletal and nuclear responses. Science 274: 2115-2118.

Chen, Y.P., Hsiao, P.J., Hong, W.S., Dai, T.Y. and Chen, M.J., 2012. Lactobacillus kefiranofaciens M1 isolated from milk kefir grains ameliorates experimental colitis in vitro and in vivo. Journal of Dairy Science 95: 63-74.

Coconnier, M.H., LieVin, V., Lorrot, M. and Servin, A.L., 2000. Antagonistic activity of Lactobacillus acidophilus LB against intracellular Salmonella enterica serovar Typhimurium infecting human enterocyte-like Caco-2/TC-7 cells. Applied and Environmental Microbiology 66: 1152-1157.

Collado, M.C., Meriluoto, J. and Salminen, S., 2007. Role of commercial probiotic strains against human pathogen adhesion to intestinal mucus. Letters in Applied Microbiology 45: 454-460.

Collado, M.C., Meriluoto, J. and Salminen, S., 2008. Adhesion and aggregation properties of probiotic and pathogen strains. European Food Research Technology 226: 1065-1073.

Del Re, B., Busetto, A., Vignola, G., Sgorbati, B. and Palenzona, D.L., 1998. Autoaggregation and adhesion ability in a Bifidobacterium suis strain. Letters in Applied Microbiology 27: 307-310.

Fernandez, M., Boris, S. and Barbes, C., 2003. Probiotic properties of human lactobacilli strains to be used in the gastrointestinal tract. Journal of Applied Microbiology 94: 449-455.

Ferreira, C.L., Grzeskowiak, L., Collado, M.C. and Salminen, S., 2011. In vitro evaluation of Lactobacillus gasseri strains of infant origin on adhesion and aggregation of specific pathogens. Journal of Food Protection 74: 1482-1487.

Ferreira-Zanirati, D., Abatemarco, M., De Cicco Sandes, S., Nicoli, J.R., Cantini Nunes, A. and Neumann, E., 2015. Selection of lactic acid bacteria from Brazilian kefir grains for potential use as starter or probiotic cultures. Anaerobe 32: 70-76.

Finlay, B.B., Ruschkowski, S. and Dedhar, S., 1991. Cytoskeletal rearrangements accompanying Salmonella entry into epithelial cells. Journal of Cell Science 99: 283-296.

Foligné, B., Daniel, C. and Pot, B., 2013. Probiotics from research to market: the possibilities, risks and challenges. Current Opinion on Microbiology 16: 284-292.

Garrote, G.L., Abraham, A.G. and De Antoni, G.L., 2001. Chemical and microbiological characterisation of kefir grains. Journal of Dairy Research 68: 639-652.

Ginocchio, C., Olmsted. S.B., Wells, C.L. and Galán, J.E., 1994. Contact with epithelial cells induces the formation of surface appendages on Salmonella Typhimurium. Cell 76: 717-724.

Goh, Y.J. and Klaenhammer, T.R., 2010. Functional roles of aggregationpromoting-like factor in stress tolerance and adherence of Lactobacillus acidophilus NCFM. Applied and Environmental Microbiology 76: 5005-5012.

Golowczyc, M.A., Gugliada, M.J., Hollmann, A.J., Delfederico, L., Garrote, G.L., Abraham, A.G., Semorile, L. and De Antoni, G., 2008. Characterization of homofermentative lactobacilli isolated from kefir grains: potential use as probiotic. Journal of Dairy Research 75: 211-217. 
Golowczyc, M.A., Mobili, P., Garrote, G.L., Abraham, A.G. and De Antoni, G.L., 2007. Protective action of Lactobacillus kefir carrying S-layer protein against Salmonella enterica serovar Enteritidis. International Journal of Food Microbiology 118: 264-273.

Granato, D., Branco, G.F., Nazzaro, F., Cruz, A.G. and Faria, J.A.F., 2010. Functional foods and nondairy probiotic food development: trends, concepts, and products. Comprehensive Reviews on Food Science 9: 292-302.

Gueimonde, M., Jalone, L., He, F., Hiramatsu, M. and Salminen, S., 2006. Adhesion and competitive inhibition and displacement of human enteropathogens by selected lactobacilli. Food Research International 39: 467-471.

Guignot, J., Caron, E., Beuzón, C., Bucci, C., Kagan, J., Roy, C. and Holden, D.W., 2004. Microtubule motors control membrane dynamics of Salmonella containing vacuoles. Journal of Cell Science 117: 1033-1045.

Gulitz, A., Stadie, J., Wenning, M., Ehrmann, M.A. and Vogel, R.F., 2011. The microbial diversity of water kefir. International Journal of Food Microbiology 151: 284-288.

Hamet, M.F., Londero, A., Medrano, M., Vercammen, E., Van Hoorde, K., Garrote, G.L., Huys, G., Vandamme, P. and Abraham, A.G., 2013. Application of culture-dependent and culture-independent methods for the identification of Lactobacillus kefiranofaciens in microbial consortia present in kefir grains. Food Microbiology 36: 327-334.

Hamet, M.F., Piermaria, J.A. and Abraham, A.G., 2015. Selection of EPS-producing Lactobacillus strains isolated from kefir grains and rheological characterization of the fermented milks. LWT - Food Science and Technology 63: 129-135.

Kakisu, E.J., Abraham, A.G., Tironi, V., Farinati, C., Ibarra, C. and De Antoni, G.L., 2012. Lactobacillus plantarum isolated from kefir protects Vero cells from cytotoxicity by type II shiga toxin from Escherichia coli O157:H7. Journal of Dairy Research 80: 1-8.

Koninkx, J.F.J.G., Tooten, P.C.J. and Malago, J.J., 2010. Probiotic bacteria induced improvement of the mucosal integrity of enterocyte-like Caco-2 cells after exposure to Salmonella Enteritidis 857. Journal of Functional Foods 2: 225-234.

Lahtinen, S. and Ouwehand, A., 2009. Adhesion to intestinal mucus and epithelium by probiotics. In: Lee, Y.K. and Salminen, S. (eds.) Handbook of probiotics and prebiotics, $2^{\text {nd }}$ edition. Wiley, Hoboken, NJ, pp. 377-384.

Lebeer, S., Vanderleyden, J. and De Keersmaecker, S.C.J., 2010. Host interactions of probiotic bacterial surface molecules: comparison with commensals and pathogens. Nature Reviews in Microbiology 8: $171-184$

Lee, Y.K., Puong, K.Y., Ouwehand, A.C. and Salminen, S., 2003. Displacement of bacterial pathogens from mucus and Caco-2 cell surface by lactobacilli. Journal of Medical Microbiology 52: 925-930.

Li, P., Yu, Q., Ye, X., Wang, Z. and Yang, Q., 2011. Lactobacillus S-layer protein inhibition of Salmonella-induced reorganization of the cytoskeleton and activation of MAPK signalling pathways in Caco-2 cells. Microbiology 157: 2639-2646.

Marsh, A.J., O'Sullivan, O., Hill, C., Ross, R.P. and Cotter, P.D., 2013. Sequence-based analysis of the microbial composition of water kefir from multiple sources. FEMS Microbiology Letters 348: 79-85.
Medrano, M., Hamet, M.F., Abraham, A.G. and Pérez, P.F., 2009. Kefiran protects Caco-2 cells from cytopathic effects induced by Bacillus cereus infection. Antonie Van Leeuwenhoek Journal of Microbiology 96: 505-513.

Méresse, S., Unsworth, K.E., Habermann, A., Griffiths, G., Fang, F., Martínez Lorenzo, M.J., Waterman, S.R., Gorvel, J.P. and Holden, D.W., 2001. Remodelling of the actin cytoskeleton is essential for replication of intravacuolar Salmonella. Cell Microbiology 3: 567577.

Miguel, M.G.C.P., Cardoso, P.G., Lago, L.A. and Schwan, R.F., 2010. Diversity of bacteria present in milk kefir grains using culturedependent and culture-independent methods. Food Research International 42: 1523-1528.

Otero, M.C., Ocaña, V.S., Elena Nader-Macías, M., 2004. Bacterial surface characteristics applied to selection of probiotic microorganisms. Public Health Microbiology 268: 435-440.

Pérez, P.F., Minnaard, J., Disalvo, E.A. and De Antoni, G.L., 1998. Surface properties of bifidobacterial strains of human origin. Applied and Environmental Microbiology 64: 21-26.

Pidoux, M., Marshall, V.M., Zanoni, P. and Brooker, B., 1990. Lactobacilli isolated from sugary kefir grains capable of polysaccharide production and minicell formation. Journal of Applied Bacteriology 69: 311-320.

Polak-Berecka, M., Wasko, A., Paduch, R., Skrzypek, T. and SrokaBartnicka, A., 2014. The effect of cell surface components on adhesion ability of Lactobacillus rhamnosus. Antonie Van Leeuwenhoek Journal of Microbiology 106: 751-762.

Powell, J.E., Witthuhn, R.C., Todorov, S.D. and Dicks, L.M.T., 2007. Characterization of bacteriocin ST8KF produced by a kefir isolate Lactobacillus plantarum ST8KF. International Dairy Journal 17: 190-198.

Santos, A., SanMauro, N., Sanchez, A., Torres, J.M. and Marquina, D., 2003. The antimicrobial properties of different strains of Lactobacillus spp. isolated from kefir. Systematic and Applied Microbiology 26: 434-437.

Servin, A.L., 2004. Antagonistic activities of lactobacilli and bifidobacteria against microbial pathogens. FEMS Microbiology Reviews 28: 405-440.

Schär-Zammaretti, P. and Ubbink, J., 2003. The cell wall of lactic acid bacteria: surface constituents and macromolecular conformations. Biophysics Journal 85: 4076-4092.

Schierack, P., Kleta, S., Tedin, K., Babila, J.T., Oswald, S., Tobias, A., Oelschlaeger, R.H., Paetzold, S. and Wieler, L.H., 2011. E. coli Nissle 1917 affects Salmonella adhesion to porcine intestinal epithelial cells. PLoS ONE 6: 1-10.

Schillinger, U., Guigas, C., Holzapfel, W.H., 2005. In vitro adherence and other properties of Lactobacilli used in probiotic yoghurt-like products. International Dairy Journal 15: 1289-1297.

Steele-Mortimer, O., Brumell, J.H., Knodler, L.A., Méresse, S., Lopez, A. and Finlay, B.B., 2002. The invasion-associated type III secretion system of Salmonella enterica serovar Typhimurium is necessary for intracellular proliferation and vacuole biogenesis in epithelial cells. Cell Microbiology 4: 43-54. 
Tareb, R., Bernardeau, M., Gueguen, M. and Vernoux, J.P., 2013. In vitro characterization of aggregation and adhesion properties of viable and heat-killed forms of two probiotic Lactobacillus strains and interaction with foodborne zoonotic bacteria, especially Campylobacter jejuni. Journal of Medical Microbiology 62: 637-649.

Valeriano, V.D., Parungao-Balolong, M.M. and Kang, D.K., 2014. In vitro evaluation of the mucin-adhesion ability and probiotic potential of Lactobacillus mucosae LM1. Journal of Applied Microbiology 117: 485-497.
Walter, J., Schwab, C., Loach, D., Gänzle, M. and Tannock, G., 2008. Glucosyltransferase A (GtfA) and inulosucrase (Inu) of Lactobacillus reuteri TMW1.106 contribute to cell aggregation, in vitro biofilm formation, and colonization of the mouse gastrointestinal tract. Microbiology 154: 72-80.

Yu, Q., Yuan, L., Deng, J. and Yang, Q., 2015. Lactobacillus protects the integrity of intestinal epithelial barrier damaged by pathogenic bacteria. Frontiers in Cell Infection Microbiology 5: 26.

Xu, H., Jeong, H.S., Lee, H.Y. and Ahn, J., 2009. Assessment of cell surface properties and adhesion potential of selected probiotic strains. Letters in Applied Microbiology 49: 434-442. 
